\title{
Author Correction: The role of energy storage in deep decarbonization of electricity production
}

\author{
Maryam Arbabzadeh', Ramteen Sioshansi², Jeremiah X. Johnson ${ }^{3}$ \& Gregory A. Keoleian (1) ${ }^{1}$
}

Correction to: Nature Communications https://doi.org/10.1038/s41467-019-11161-5, published online 30 July 2019.

The original version of this Article contained an error in Figs. 3 and 4, in which all $y$-axis labels incorrectly included 'Emissions reduction (million ton)' rather than the correct 'Total emissions (million ton)'. This has been corrected in both the PDF and HTML versions of the Article.

Published online: 26 August 2019

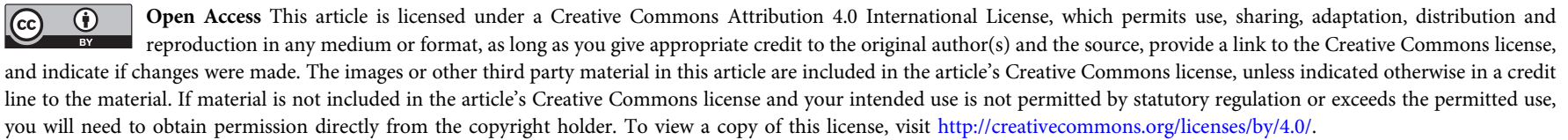

(C) The Author(s) 2019

\footnotetext{
${ }^{1}$ Center for Sustainable Systems, School for Environment and Sustainability, University of Michigan, Ann Arbor, 48109 MI, USA. ${ }^{2}$ Department of Integrated Systems Engineering, The Ohio State University, Columbus, 43210 OH, USA. ${ }^{3}$ Department of Civil, Construction, and Environmental Engineering, North Carolina State University, Raleigh, 27607 NC, USA. Correspondence and requests for materials should be addressed to M.A. (email: marbab@umich.edu)
} 